\title{
PROJETO ARQUITETÔNICO DE UM EDIFÍCIO ESCOLAR COM ÊNFASE NA ARQUITETURA SENSORIAL - EM PRESIDENTE PRUDENTE - SP.
}

\author{
Dayane Tieme Yamada Carrenho, Djanine Dolovet Martins. \\ Universidade do Oeste Paulista - UNOESTE, Faculdade de Engenharias e Arquitetura e Urbanismo, \\ Presidente Prudente, SP. E-mail: dayaneyamada@yahoo.com.br.
}

\begin{abstract}
RESUMO
O presente trabalho sintetiza estudos e abordagens contundentes a projeção de uma edificação escolar, que acompanhe os preceitos relativos ao contexto da sociedade atual. Onde os espaços escolares apresentam potencialidades integradoras entre a comunidade, onde a escola evoca sentimentos de identidade e pertencimento, na qual está inserida. A escola a ser projetada deve acompanhar os movimentos sociais da atualidade, onde evoca-se a questão da inclusão social de crianças especiais no ensino regular, discutindo vertentes que vão além das normas vigentes de acessibilidade. Todos os estudos levantados serão, interpretados pela arquitetura através de ambientes condizentes a pedagogia, e que seja capaz de despertar todos os sentidos coagnitivos, ou seja, uma arquitetura sensorial.
\end{abstract}

Palavras-chave:Arquitetura Escolar. Educação. Escola e Comunidade. Inclusão Social. Arquitetura Sensorial.

\begin{abstract}
This work synthesizes studies and compelling approaches the projection of a school building, which follow the provisions relating to the current society context. Where school spaces have integrative potential of the community where the school evokes feelings of identity and belonging in which it operates. The school is designed to accompany the social movements of our time, where it is evokes the question of social inclusion of special children in regular schools, discussing aspects that go beyond the current accessibility standards. All studies are, played by architecture through in agreement environments with this education, and to be able to awaken all senses, ie a sensory architecture.
\end{abstract}

Keywords:School architecture. Education. School and Community. Social inclusion. Sensory Architecture. 


\section{INTRODUÇÃO}

Este trabalho apresenta estudos e reflexões relativas a arquitetura escolar sensorial, no qual faz parte do Trabalho de conclusão de curso de arquitetura e urbanismo, onde, todos estudos apresentados vão auxiliar na composição e direcionamento da proposta projetual a ser concebida posteriormente, para um lote implantado na cidade de Presidente Prudente - SP.

Falar em educação, mais especificamente nos preceitos em que uma instituição escolar carrega, é associar sua relevância social e cultural dentre a formação da sociedade e respectivamente do indivíduo, o cidadão. Na qual a escola tem papel de suma importância na vida da criança e respectivamente do ser humano.

Para Frias (2008), a qualidade de vida oferecida na educação não só remete a questões de redimensionamento, mas como também de aceitação e valorização das diferenças, tal valorização tem o poder de resgatar questões culturais, que fortalecem a identidade e o respeito do indivíduo.

A escola não é só um local onde se aprende o que é estabelecido no cronograma pedagógico, o aluno vai além das ciências, a escola é um espelho da sociedade, onde ele aprende a conviver e lidar com a diversidade, e é lá que ele não só aprende, mas também começa a por em prática lições de cidadania e democracia.

Com isso, este estudo abordará questões que se faz refletir sobre uma arquitetura que seja explorada em todos os sentidos cognitivos dos pequenos, uma arquitetura que vá além do sentido visual, na qual possa evocar emoções e sensações.

Para Gonçalves (1999),Este espaço carregado de significados onde as relações humanas se estabelecem é, pois, um pano de fundo, a moldura sobre a qual as sensações se revelam e produzem marcas profundas que permanecem por toda a vida.

E é pensando nesses preceitos, delongados através deste trabalho teórico, em que a proposta projetual se baseara, objetivando apresentar uma arquitetura escolar que contribua não só para a aprendizagem, mas para a vivência dos futuros cidadãos. Na qual se possa levantar questionamentos pertinentes à arquitetura como um espaço físico intermediador de vivências, sensações e integrações entre a comunidade, através de quais meios ela possa oferecer ambientes que contribuam para a aprendizagem e qualidade na vivência dos pequenos.

Com isso, as abordagens apresentadas ao longo deste trabalho, enfatizam o quanto a edificação escolar, pode vir a ser um equipamento urbano potencializador entre a integração da escola e a comunidade em que ela está inserida. Quando um projeto escolar se abre à comunidade, a mesma eleva o sentimento de pertencimento e de identidade diante do edifício.

Os estudos levantados e apresentados ao longo deste trabalho auxiliarão na concepção da proposta a ser concebida e apresentada, pontuando a importância de se apresentar uma escola que seja voltada para "todos", remetendo as questões de inclusão social de crianças especiais em meio ao ensino regular, tema que têm ganhando cada vez mais espaço na sociedade.

Para que que seja pontuado espaços que vão além da acessibilidade, onde possam proporcionar e evocar os sentidos, através de ambientes estimulantes, que remetam sensações de aconchego e acolhimento, e instigue a curiosidade, através de uma arquitetura sensorial, despertando os cinco sentidos.

\section{METODOLOGIA}

Este trabalho foi desenvolvido metodologicamente através delevantamentos bibliográficos, pesquisa documental, junto a pesquisas pedagógica, e análise de contexto local através de mapas e visitas, onde está implantado o terreno, na cidade de Presidente Prudente.

Para compor tal pesquisa, também foram necessários levantamentos e análises detalhadas dentre projetos de edificação escolar com destaques arquitetônicos, nos quais são alinhados com as respectivas metodologias pedagógicas em que atendem. 
Todo material pesquisado e analisado neste trabalho, visam nortear todo o desenvolvimento de conteúdo teórico, para que seja assentada as bases para a futura proposta projetual a ser concebida.

\section{ARQUITETURA SENSORIAL.}

Comenius foi o primeiro a organizar um programa de escolarização universal, segundo Kowaltowski (2011) além de ele pregar uma pedagogia onde a escola, o professor e a família deviam ser um elo do processo educativo, Comenius enfatizava a importância do ambiente escolar arejado, bonito, com espaços livres e ecológicos onde, a aprendizagem se iniciasse pelos sentidos, para que posteriormente, quando essas experiências sensoriais fossem interiorizadas, seriam interpretadas pela razão. "O homem, não se constitui apenas de intelecto, pois as disposições primitivas como as emoções, os sentidos, os instintos e os sentimentos existem antes do pensamento elaborado" (Kowaltowski 2011, p. 17).

Para Kowaltowski (2011) "A interação do homem com o meio causa efeitos diretos, que irão nortear seu modo de vida". A autora ainda complementa que a psicologia ambiental envolvem questões relativas a sociologia, ergonomia, antropologia, além da engenharia e planejamento da arquitetura.

Pensando nisso, o arquiteto deve ir além de normas, do conforto termo acústico e visual, ele deveria sair da caixa, projetar não só espaços, mas vivências ali a serem inseridas, ir ao intangível, promover aquilo que não se vê, mas se sente, e faz o usuário evoluir principalmente dentro de um espaço tão importante para o ser humano, a escola. Onde Gonçalves (1999, p. 52) ainda conclui que:

O arquiteto ao desenhar/projetar o espaço escolar expressa ali sua objetividade e subjetividade no intuito de satisfazer as exigências espaciais dos que ali vão trabalhar [...] São exigências também psicológicas e estéticas, ligadas ao comportamento, ao modo do uso do espaço, ao significado simbólico e prático que ali se atribui.

Um ambiente pode influenciar diretamente no fator sensorial e conseqüentemente comportamental do homem. Tal ambiente pode motivar estimular, e provocar sensações e reações relacionadas aos estímulos externos, pois somados aos estímulos internos direcionam ao comportamento do indivíduo (OKAMOTO, 2002).

O ser humano é estimulado a todo o momento graças à sensação que o ambiente proporciona, inconscientemente. Ainda de acordo com Okamoto (2002), no sentido sensorial há apenas os estímulos coletados, sem que tenha a percepção, pois são sensações que ainda chegaram a consciência. Há consciência quando tais aspectos e sensações chamam a atenção do usuário a ponto que faça perceber no ambiente em que esteja inserido. A interpretação sensorial que cada ser humano tem é diferente, pois, depende das vivencias, emoções e motivações que cada um possui.

A criança trabalha o corpo e a mente de maneira conjunta, que com a inserção da linguagem ela é apresentada a sociedade chegando à etapa de condicionamento e modelos impostos pela sociedade, no qual de ativa passa a ser passiva.Sendo assim, considera-se que a realidade interpretada de maneira equilibrada é aquela na qual onde os receptores externos, sentidos sensoriais de percepção e valores são considerados simultaneamente (OKAMOTO, 2002).

A realidade do meio ambiente é mostrada através da intensa vivência conjunta do corpo e mente, utilizando fatores abstratos e simbólicos construindo assim sua própria visão de mundo através dos sentidos internos e externos. Gonçalves $(1999$, p.51) ainda observa:

Este espaço carregado de significados onde as relações humanas se estabelecem é, pois, um pano de fundo, a moldura sobre a qual as sensações se revelam e produzem marcas profundas que permanecem por toda a vida. 
$\mathrm{Na}$ arquitetura escolar, as barreiras ali inseridas têm o poder de impedir a igualdade de educação entre os desiguais. Assim, cabe a nós arquitetos promover a igualdade através de todas as ferramentas que contemos, saindo do meio comum e indo além para poder promover a igualdade da sociedade (GONÇALVEZ, 1999).

Para Martau (apud PALLASMAA, 2005),Pallasma defende em seu livro, uma arquitetura de experiências multissensoriais, oposta da arquitetura "visual" que se apresenta na maioria dos edifícios. O autor defende que os sentidos devem estar presentes na expressão e experiências arquitetônicas.

$O$ autor segue fazendo uma crítica que grande parte da arquitetura que se faz presente, está focada em apenas um sentido: a visão. Martau (apud PALLASMAA, 2005) ressalta que nossa percepção sobre o mundo está embutida nas informações que recebemos através dos cinco sentidos, e que ambos devem ser explorados. A arquitetura deve equilibrar-se entre a funcionalidade, conforto e os sentidos, de modo que motive a imaginação e a emoção.

\section{ANTECEDENTES PROJETUAIS}

Para auxiliar na concepção conceitural da proposta a ser apresentada, foram selecionados criteriosamente três antecedentes projetuais, nos quais cada um apresenta destaques a serem pontuados e evocados na confecção do projeto a ser elaborado.Cada referência pontua algo que inspirara o processo de criação projetual, na referência da Creche Guastalla, de Mario Cucinella o destaque vai para as questões sensoriais elevadas ao caráter arquitetônico e paisagístico, já a referência da Escola Parque Dourado $V$, do escritório Apiacás traduz através do projeto, a integração entre a escola e a comunidade de modo simples e harmônico. Por fim, a terceira referência - Escola Infantil Elefante Amarelo, do escritório XYStudio, apresenta uma arquitetura com destaque voltado para a escala das crianças, alinhada a pedagogia aplicada.

\section{ESCOLA GUASTALLA}

Inaugurada em 2015, a Escola Guastalla, projetada pelo arquiteto italiano Mario Cucinella, reconhecido por seus projetos de caráter sustentável e de baixo impacto, a escola é mais um exemplar de tal estilo, apresentando uma arquitetura baseada não só com diretrizes sustentáveis, mas inovadora, envolvente e surpreendente. O projeto foi idealizado para que ocorresse a estimulação sob a interação da criança e o espaço em que ela está inserida. Das escolhas dos materiais a distribuição dos ambientes, foi-se pensado minuciosamente para que se torne a questão do "ensinar", como algo totalmente envolvente.

O projeto em si gera uma referência como um todo, o respeito e a interconexão em relacionar a pedagogia aplicada à arquitetura é um ponto a ser exaltado, outros fatores que chamam atenção para serem empregados no projeto a ser elaborado posteriormente é a questão da sustentabilidade, tema tão atual e que se faz necessário no contexto mundial. O cuidado em estudar o conforto térmico, a escolha dos materiais, e a integração constante entre os ambientes são outros pontos a serem aplicados nas etapas seguintes deste trabalho.

E por último o ponto chave, que coroa todo o projeto é a questão sensorial que o ambiente permite ao usuário, desde elementos internos, com design diferenciado ao jardim que evoca todos os sentidos, tornando-se um fator a ser alavancado ao decorrer deste trabalho, a escola de Cucinella ultrapassa a barreira visual e se transpõe ao intangível, aos sentidos, a uma poesia materializada que vai além do ver, podendo ser sentida.

\section{ESCOLA PARQUE DOURADO V.}

Implantada em uma zona periférica de Ferraz de Vasconcelos - SP, a Escola Parque Dourado compõe um projeto do ano de 2007 , concebido junto a uma praça e um auditório. A área 
de implantação era um lugar de passagem informal que ficava entre uma escola e uma quadra muito utilizados pela comunidade local, partindo de tal premissa o escritório de arquitetura Apiacás sob o pedido do FDE, desenvolveu um projeto de edificio escolar que se integrasse a comunidade e formalizasse o até então "beco de passagem" (APIACÁS ARQUITETOS, 2007).

Partindo da diretriz integrativa, a escola foi projetada de forma paralela a passagem da comunidade, onde a mesma possui uma quadra esportiva coberta, aberta e totalmente integrada ao exterior, na qual além dos alunos a comunidade possa usufruir aos finais de semana.Para Kowaltowski (2011), a boa arquitetura escolar, é a expressão dos fatores estéticos, formais, e conceituais, aonde ela vai além, sendo reconhecida pela sua representatividade, tornando-se papel de influência no seu entorno social, assumindo assim sua identidade diante da coletividade.

Esta escola se encaixa ao que Kowaltowski se refere a questão do papel que uma boa escola, através da arquitetura possa representar para a sociedade, ela não só ressalta uma identidade para aquela comunidade, como também se abre a população daquela área de forma integradora. A integração perpassa as questões da arquitetura relativas ao "interno x externo", ela vai além e alcança o intangível: a esfera social, traçando um relacionamento entre o edifício e a comunidade como um todo.

\section{ESCOLA INFANTIL ELEFANTE AMARELO.}

Localizada na Polônia em uma pequena cidade chamada, OstrówMazowiecka, o jardim de infância chamado (e traduzido) Elefante Amarelo foi projetado pelo escritório também polonês XYStudio, em 2015 (BRANT, 2016).Todas as alturas das entradas, aos parapeitos, e cobertura seguiram o partido projetual referente a escala reduzida.

Tal preocupação quanto à escala, surgiu através da premissa em que a escola devesse apresentar um ambiente mais doméstico ao entrar ao edifício, assim as alturas dentre os ambientes foram reduzidas ao máximo, para que as crianças pudessem sentir que a escola foi feita para elas.Os fatores de integração que envolvem esse projeto, desde a preocupação à escala, a configuração e mobiliário que a salas se apresentam de forma lúdica nos quais, os ambientes livres são pontos base, para ser levado a proposta projetual a ser apresentada como conclusão deste trabalho.

\section{CONCLUSÃO}

O presente trabalho partiu da premissa através de reflexões e questionamentos sobre o papel da escola na sociedade atual, e assim seu contexto, adjunto a influência que a arquitetura educacional possa proporcionar na vivência e no aprendizado dos alunos. A arquitetura é uma ferramenta, quando alinhada à metodologia de ensino, transformadora e capacitadora, capaz de transpor o intangível. Propiciando uma integração, ou seja, um elo não só imbuído no aluno, como na comunidade pertencente.

A educação é uma escada da evolução social, e é pensando nisso que nós arquitetos temos o papel de transpassar pelo projeto, relações que enalteçam o laço entre as futuras gerações e o papel da escola. Por isso, se faz tão importante ir além, oferecendo espaços que toquem e estimulem as crianças, que as motive, e as façam sentir e entender que escola ao mesmo tempo, que possa ser um abrigo é também um local de aventuras a serem desbravadas e descobertas todos os dias.

\section{REFERÊNCIAS}

APIÁCAS, A. Escola estadual Parque Dourado V. 2007. Disponível em: <http://apiacasarquitetos.com.br/projetos/ver/18/desenhos/fullscreen/page/4.>. Acesso em: 15 mai. 2016. 
BRANT, J. Jardim de infância Elefante Amarelo. 2016. Diponível em: <http://www.archdaily.com.br/br/786789/jardim-de-infancia-yellow-elephant-xystudio.> Acesso em: 16 mai. 2016.

FRIAS, E. M. A. Inclusão escolar do aluno com necessidades especiais: contribuições ao professor do ensino regular. 2008. Disponível em: < http://www.diaadiaeducacao.pr.gov.br>. Acesso em 28 nov. 2015.

GONÇALVES, R. C. A Arquitetura escolar como materialidade do direito desigual à educação. Ponto de Vista, v. 1, n. 1, julho/dez., 1999. Disponível em: <https://periodicos.ufsc.br/index.php/pontodevista/article/view/1520>. Acesso em: 26 set. 2015.

KOWALTOWSKI, D. C. C. K. Arquitetura escolar: o projeto do ambiente de ensino. São Paulo: Oficina textos, 2011.

MARTAU, B. T. A arquitetura multisensorial de JuhaniPallasmaa. Arquiteturarevista, São Leopoldo

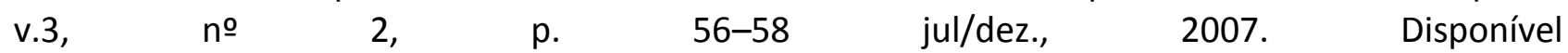
em:<http://revistas.unisinos.br/index.php/arquitetura>. Acesso em 05 mai. 2016.

OKAMOTO, J. Percepção ambiental e comportamento: visão holística da percepção ambiental na arquitetura e na comunicação. São Paulo: Mackenzie, 2002. 